\title{
Concepçôes dos agentes comunitários de saúde sobre suas práticas assistenciais
}

\section{| ${ }^{1}$ Marilisa Baralhas, ${ }^{2}$ Maria Alice Ornellas Pereira |}

Resumo: O presente estudo objetivou identificar as representações elaboradas por agentes comunitários de saúde (ACS) acerca de suas práticas assistenciais. Utilizamos a metodologia qualitativa de pesquisa, adotando, como instrumento de coleta de dados, a entrevista semiestruturada e, para a interpretação dos dados, recorremos à Análise Temática. Foram ouvidos 12 ACS das Equipes do Programa de Agentes Comunitários de Saúde (PACS) de um município do interior paulista. O material obtido permitiu verificar como temas: o vínculo como instrumento de trabalho e a prática pautada na promoção da saúde e na prevenção das doenças. Os relatos demonstram a importância do vínculo na prática diária, enfatizam os princípios humanitários que embasam as ações de solidariedade, destacam o sentimento de gratificação quando o trabalho executado é reconhecido pelas famílias e revelam que os sujeitos ouvidos têm dificuldades para discernir o alcance de seus limites. Embora estes profissionais apresentem um bom suporte técnico para o cumprimento de suas ações, também demonstram carência na instrumentalização para o exercício profissional. Concluímos que as diretrizes e normas estabelecidas para o PACS funcionam como norteadoras do processo de assistência, mas ainda não respondem a questões mais subjetivas encontradas na assistência ao indivíduo-famíliacomunidade. Além disso, os ACS parecem estar vulneráveis às flutuações de gestão dos municípios, estados e Governo Federal, apresentam inconsistência na ideologia do desempenho do próprio papel e não conseguem inverter o modelo assistencial pautado na doença e na intervenção médica individual.

> Palavras-chave: agentes comunitários de saúde; vínculo; humanização.

\footnotetext{
1 Professora do Curso de Enfermagem do Unisalesiano Lins; mestre em Enfermagem pela Faculdade de Medicina de Botucatu, Universidade Estadual Paulista (UNESP). Endereço eletrônico: baralhas@ uol.com.br

2 Professora adjunta, Faculdade de Medicina de Botucatu, Departamento de Enfermagem, UNESP. Endereço eletrônico: malice@fmb.unesp.br
}

Recebido em: 10/06/2009. Aprovado em: 21/06/2010. 


\section{Introdução}

O processo de construção do Sistema Único de Saúde (SUS) emerge como resultante de um conjunto de embates políticos e ideológicos, ocorridos com a participação de diferentes atores sociais ao longo dos anos. Nessa dinâmica transformadora surge em 1991, proposto pelo Ministério da Saúde, o Programa de Agentes Comunitários de Saúde (PACS) e, em 1994, o Programa Saúde da Família (PSF), como uma estratégia de reorganização sanitária, fomentando as discussōes acerca do modo de produzir saúde.

O PACS e o PSF têm atuação e abrangência definida. Cada um com sua atribuição específica, sendo que a equipe do PACS pode ser composta por até 30 ACS (contando com um enfermeiro supervisor/coordenador), enquanto que o PSF conta com um grupo multiprofissional composto de médico, enfermeiro, auxiliar/ técnico de enfermagem e até 12 agentes comunitários de saúde para cada quatro mil pessoas, podendo ser inseridos profissionais de saúde bucal, como odontólogo, auxiliar de consultório dentário e técnico de higiene dental (BRASIL, 2006).

No entanto, ambas as estratégias possuem, em comum, a figura do ACS, que teve a profissão regulamentada em 10 de julho de 2002, com a Lei no 10.507 , e que é responsável pelo acompanhamento de 750 pessoas determinadas de acordo com a área de abrangência da unidade de saúde. A mesma lei determina os requisitos necessários para o cargo de ACS: ser morador da área de atuação há pelo menos dois anos, ter completado o ensino fundamental, ser maior de 18 anos e concluir de forma satisfatória o curso introdutório para as equipes de PACS/PSF (BRASIL, 2002). As atribuições dos ACS foram reeditadas a partir desta lei e, em 28 de março de 2006, pela Portaria GM n 648 do Ministério da Saúde, ficaram estabelecidas as atividades a serem executadas por esses agentes.

A atuação do ACS está baseada em duas dimensões principais: uma, relacionada ao componente técnico; e outra, mais ao político. O componente técnico relaciona-se ao atendimento de indivíduos e suas famílias, à intervenção para prevenção de agravos ou para o monitoramento de grupos ou problemas específicos; já o político se refere a questōes relacionadas à organização da comunidade e às transformações dessas condições (SILVA; DALMASO, 2002).

$\mathrm{Na}$ prática diária dos ACS, verifica-se que esses profissionais se comprometem com o cuidado à família e se responsabilizam por ela, utilizando diversos mecanismos, dentre eles a formação de vínculo com os usuários e as famílias; 
estratégias de relacionamento interpessoal que envolvem comportamento humanizado e acolhedor; e as atividades de educação em saúde, que permitem uma elevação do autocuidado da população.

Outro aspecto relevante sobre o trabalho dos ACS se refere aos limites de atuação desses profissionais. Vê-se que tais limites são determinados pelas políticas locais, como também pelo fato de a família ou indivíduo assistido não se comprometer em cuidar de seu próprio bem-estar, ou da saúde de um ente familiar. Tal comportamento de transferência dos problemas de saúde para os profissionais, principalmente para os ACS, que estão a todo tempo em contato com a população, pode dificultar as ações de trabalho, pois estes podem não conseguir efetivar suas propostas de prevenção e promoção da saúde.

Lunardelo (2004) aponta esse aspecto, ressaltando que os ACS estabelecem uma relação igualitária com a comunidade, seja na proximidade física, intelectual ou social das famílias e dos indivíduos, refletindo no seu trabalho, na criação de vínculos, na compreensão do ser e no entendimento da complexidade do meio onde vivem estas pessoas. Martines (2005) também demonstra isso, ao observar que os ACS não conseguem discernir sobre seus limites, com relação à criação de vínculo, fato que os leva a vivenciar sensações e sentimentos como impotência, cansaço e solidão.

Considerando a importância do ACS no cenário da assistência e com o intuito de fomentar a reflexão a respeito do trabalho desenvolvido por esse profissional, este estudo, que é parte de uma pesquisa mais ampla, intitulada $O$ agente comunitário de saúde: representaçôes e dificuldades acerca da prática cotidiana da assistência, teve como objetivo identificar as representações elaboradas pelos ACS acerca de suas práticas de saúde.

\section{Metodologia}

Foi utilizada, no estudo, a metodologia qualitativa, adotando-se como instrumento de coleta de dados a entrevista semiestruturada, com o uso do gravador para o registro das falas; e, na análise dos dados, recorreu-se à Análise Temática (BARDIN, 1994).

\section{Local do estudo}

O estudo ocorreu em um município do interior paulistano, com população de 70.555 habitantes, e que teve a implantação do PACS no ano de 2000. Em junho 
de 2002, com a integração deste ao Programa de Combate à Dengue, foi ampliado o número de ACS no município; desta forma, o programa passou a contar com 67 ACS, número que prevaleceu até novembro de 2006. A partir de dezembro do mesmo ano, devido à necessidade de ampliação e extensão de cobertura, o programa passou a ter 112 ACS distribuídos em todo o município, alocados em cinco UBS. No período de coleta de dados, a cobertura do PACS em todo o município, ou seja, na área de atuação das cinco equipes, correspondia a 16.505 famílias cadastradas, totalizando 52.433 pessoas, com cobertura de $75,4 \%$ da população.

\section{Sujeitos da pesquisa}

Foram entrevistados 12 ACS, que se encontravam inseridos em quatro equipes do município. Como critério para escolha dos sujeitos, a fim de se evidenciar a essencialidade do trabalho para o ACS, foi considerado o tempo de trabalho junto ao PACS, sendo determinado o tempo mínimo de um ano de experiência no programa, como também a participação no Treinamento Introdutório e no Curso de Formação Inicial do Agente Comunitário de Saúde - Etapa I. Estipulado esse critério, e após a realização do convite, recorremos à manifestação voluntária dos interessados em participar da pesquisa. $\mathrm{O}$ tamanho da amostra foi definido pela saturação das respostas de acordo com os pressupostos da pesquisa qualitativa.

Todos os sujeitos ouvidos eram do sexo feminino, podendo este fato ser justificado pelo forte predomínio de ACS mulheres nas equipes do local onde foi realizado o estudo. Quanto à faixa etária, observamos uma variação entre 26 e 56 anos, com maior concentração na faixa etária entre 40 a 47 anos. Quando avaliamos o aspecto relacionado ao nível de escolaridade, identificamos que quase todos os entrevistados possuem o ensino médio completo. Destaca-se que duas entrevistadas concluíram o nível superior. Quanto ao tempo de serviço, constatou-se que grande parte dos ACS possui cinco anos ou mais de experiência, o que foi fundamental para o enriquecimento dos conteúdos das falas.

\section{Coleta de dados}

Para a realização das entrevistas, uma das pesquisadoras entrou em contato com as enfermeiras responsáveis pelas equipes do PACS e agendou uma reunião com todos os ACS para apresentação do projeto. Nessa ocasião, foi feito convite para participação na pesquisa, com o agendamento dos interessados para conversarem 
com a pesquisadora num momento posterior. Seguindo essa etapa, a pesquisadora

compareceu no dia e hora marcados, na própria UBS, onde o profissional se encontrava lotado. $\mathrm{Na}$ fase de realização, antecedendo a entrevista, novamente foi esclarecido o propósito da pesquisa e, após anuência de cada sujeito mediante assinatura do termo de consentimento, realizou-se a entrevista. De acordo com as exigências da Resolução n 196/96 do Conselho Nacional de Saúde, o projeto de pesquisa foi submetido e aprovado pelo Comitê de Ética (Ofício no 626/2006). As entrevistas foram realizadas individualmente e tiveram duração aproximada de 10 minutos cada, tendo sido iniciadas em abril de 2007 e concluídas em junho do mesmo ano. Foram inseridos, no roteiro de entrevista, dados de identificação que contribuíram para a análise dos dados. As perguntas norteadoras foram: a) "Como você vê a prática cotidiana de trabalho?" e b) "O que acha mais importante no seu trabalho?”

\section{Análise dos dados}

O material obtido a partir da escuta dos sujeitos mostrou-se rico em conteúdo e permitiu identificar a elaboração dos conceitos acerca da prática da assistência.

Neste artigo, que é fragmento de uma pesquisa maior, apresentaremos a percepção elaborada pelos ACS sobre a prática cotidiana, explorando os temas: a) o vínculo como instrumento de trabalho; e b) a prática pautada na promoção da saúde e na prevenção das doenças. Cada um desses temas será discutido a seguir:

\section{a) $\mathrm{O}$ vínculo como instrumento de trabalho}

Cecílio (2001, p. 115) destaca que a criação de vínculos se constitui a partir da relação de confiança entre cada usuário e uma equipe e/ou profissional de saúde e representa "mais do que a simples adscrição a um serviço ou a inscrição formal a um programa; significa o estabelecimento de uma relação contínua no tempo, pessoal e intransferível, calorosa: encontro de subjetividades".

A importância do vínculo na prática cotidiana dos ACS se expressa nos discursos, apresentados de forma enfática, ressaltando-se a confiança entre essas relações e o quanto isso é significativo para os desdobramentos de ações frente aos problemas de saúde manifestados: "É assim, eles depositam em nós uma confiança grande, a partir do momento que eles abriram o portão ali e deixam a gente entrar” (ACS 12). 
É notória, nos relatos, a relação estabelecida entre a credibilidade do usuário frente ao ACS com o tempo de serviço destinado à comunidade. Deste modo, fica evidenciado que, com o passar do tempo de convivência entre as partes, o vínculo parece constituir-se de forma mais sólida e verdadeira.

Sabe, os primeiros contatos que tinha, dependendo você não conseguia nem entrar. Agora faz três meses que eu estou nessa área nova, tem gente que me espera na calçada. Que eu vou começar a quadra do outro lado, que eu vou... aí tem uma senhorinha mesmo, são duas, é a mãe e a filha, elas ficam me esperando no portão, para ver que hora que eu vou entrar. Sabe, isso... nossa! Para gente é ser reconhecido!.... É uma gratificação enorme... (ACS 9).

Outro aspecto demonstrado pelos entrevistados nos leva a refletir sobre a confiança entre essas relações, bem como sobre a forma indeterminada através da qual os usuários e familiares expõem questões particulares de vida. Muitas vezes, intimidades são traduzidas pelos ACS, em alguns momentos, como gratidão e reconhecimento, mas também causam estranheza, espanto e surpresa.

Mais importante... é o vínculo que a gente tem com a família, né?... São sete anos, que a família tem muita confiança, ela é capaz de falar coisas assim que você nem imagina que a pessoa vai te falar, né? (ACS 7).

Segundo Lima et al. (2007), a formação deste vínculo está submetida ao bom atendimento, baseado na escuta do usuário e no bom desempenho profissional, otimizando assim o processo da assistência, de modo a facilitar o acesso dos usuários aos serviços de saúde, à medida que os profissionais passam a conhecer seus clientes e as prioridades de cada um.

Para Bachilli, Scavassa e Spiri (2008), o cotidiano do trabalho do agente, essencialmente pautado nas visitas domiciliares, é marcado pela abordagem dos problemas detectados, sobretudo quando utilizam mecanismos como a informaçãa, a escuta, o conselho, a conversa e a conscientização para a prevenção.

Vimos que os sujeitos identificam, na visita domiciliar, momentos importantes e estratégicos para se estabelecer, com usuários e as famílias, uma relação de vínculo. Identificam esse espaço como oportunidade para a escuta das necessidades, para aproximação entre ambos, promovendo um melhor entendimento do próprio ACS sobre as questôes peculiares da família assistida naquele momento: "Bom, o que eu considero mais importante é... são as visitas mesmo, a atenção que a gente dá a cada família, o elo de ligação que nós somos entre a população assistida e a UBS...” (ACS 9). 
Meira (2008) identificou que os enfermeiros, os ACS, os médicos e os usuários consideram, como atividades fundamentais ao desempenho do agente comunitário de saúde, realizar visita domiciliar, ouvir necessidades da família e atuar como um elo entre a comunidade e a equipe de saúde. Os relatos ouvidos demonstram que os sujeitos têm certa dificuldade em colocar limites entre as ações ou atividades inerentes ao próprio trabalho e as ações solidárias.

É assim correr atrás. Às vezes o papel do agente comunitário é ter dó e comprar o remédio, tirar do bolso... como a gente vive em comunidade na igreja, fala: "Gente, tem fulana que está precisando de uma cesta básica, tem pessoa que está precisando de fralda”. Mobiliza a população para ajudar a gente naquele caso (ACS 3).

Nos discursos, os sujeitos enfatizam que, em algumas situaçóes, se colocam como amigos ou como membros da família. Essa interface do trabalho com as ações de solidariedade pode estar relacionada ao fato de a maioria dos sujeitos ter tempo de experiência significativo na profissão, participar de ações voluntárias e apresentar um comprometimento com a atividade.

Merhy (2007a) fala da tecnologia leve, caracterizada quando há um encontro entre duas pessoas, atuando uma sobre a outra, onde se cria a intersubjetividade, momentos de fala, de escuta, de interpretaçôes, cumplicidade, confiabilidade, acolhimento, produção de vínculo e aceitação. Merhy (2007b, p. 33) também considera que o ato cuidador "é um encontro intercessor entre um trabalhador de saúde e um usuário, no qual há um jogo relacional entre o mundo das necessidades, direitos, construído histórica e culturalmente, com o do agir tecnológico”. Nessa ótica, no interior de um processo de trabalho constituído de trabalhador e usuário estabelece-se entre ambos, um espaço intercessor, no qual ocorre uma "relação mútua de intervenção em ato, que existirá nos seus encontros”.

Os discursos sugerem que os nossos sujeitos, são impactados por esse encontro.

O convívio com a população, com a comunidade. A gente torna assim uma família na nossa microárea... É assim, a gente se torna tão da família, que a gente não vai assim às vezes como uma Agente Comunitária... Então a confiança... é muito bom. É muito gratificante (ACS 3).

Embasados na confiança que permeia suas relações com os usuários, os sujeitos consideram-se fundamentais na investigação dos problemas de saúde da população. Os relatos deixam transparecer certa onipotência no exercício da atenção em saúde e, por outro lado, observa-se a aproximação dos sujeitos frente às experiências corriqueiras e humanas que compõem a vida das pessoas. 
Ah, eu acho assim, que eu sou muito importante sim, porque eles passam a ter confiança em mim, passando todos os seus problemas, que a gente acaba resolvendo tudo os problemas deles numa simples conversa com eles ali. Então... eu sou importante sim, porque eu estou ali, eu estou vendo o que está acontecendo, o problema daquela família (ACS 2).

O comprometimento com a vida das pessoas, com o bem-estar das famílias e com as questôes que envolvem a comunidade em geral, pode, em alguns momentos, refletir sobre os sujeitos, na vivência de situações de sofrimento, perdas ou das inúmeras dificuldades multifatoriais presentes nos núcleos familiares, o que pode gerar o sentimento de impotência mediante a pluralidade da realidade cotidiana.

No entanto, os participantes do estudo valorizam a forma como abordam e como se relacionam com os usuários, enfatizando essa vinculação como fator primordial para executarem suas ações de saúde. Os sujeitos demonstram satisfação em estarem perto da comunidade, mesmo fora do horário de trabalho, como também se sentem gratos e satisfeitos em perceberem que esta os quer bem, pois reconhece que eles estão ali para contribuírem com o bem-estar da população.

Para Jardim (2007), o processo de conquista da credibilidade perante a população não é algo garantido e sim conquistado. $O$ fato de morar ou não na própria região não determina esse processo. $\mathrm{O}$ autor questiona as normas estabelecidas pelo Ministério da Saúde, segundo os quais o agente comunitário de saúde deve ser morador da comunidade onde irá atuar. Entretanto, Ferraz e Aerts (2005) alegam que a qualidade da relação entre o agente e a comunidade deve ser parcialmente atribuída ao tempo de sua residência no local, prevalecendo, como fator importante para a integração do ACS, a empatia como sentimento recíproco entre ele e o grupo assistido.

Martines (2005) aborda a questão do sofrimento psíquico presente na dinâmica de trabalho dos ACS e aponta que o fato de pertencerem à comunidade onde atuam pode ser mais um elemento gerador deste sofrimento. Em outras palavras, assumem o duplo papel de trabalhadores e população; têm duas identidades existindo em uma base de realidade simultânea e indissociável.

Vê-se que o cotidiano de trabalho do ACS é pautado na extensa construção de laços de confiança, credibilidade e vínculo conforme foi referenciado por Cecílio (2001). Assim, é possível identificar que tal processo ocorre a partir do convívio com as famílias, do esclarecimento da população em relação ao seu trabalho, da proposta dos serviços locais de saúde, do estímulo e do apoio dados pelos demais 
profissionais de saúde e, acima de tudo, em função do interesse e comprometimento do próprio agente em compartilhar os problemas vivenciados pela comunidade.

\section{b) A prática pautada na promoção da saúde e na prevenção das doenças}

Westphal (2006) refere que as ações de promoção da saúde devem fomentar o bem-estar físico, mental, social e espiritual, pautando-se assim em uma concepção holística voltada para a multicausalidade do processo saúde-doença, que ultrapassam os limites do setor saúde. Entretanto, a prevenção de doenças identifica e atua sobre os riscos à saúde, não considerando a origem desses riscos, o estudo de suas naturezas, os mecanismos de atuação e os meios de prevenir sua existência.

Evidencia-se, nos relatos, que os sujeitos consideram as orientações quanto à prevenção de doenças e à promoção da saúde, como atividades técnicas, estabelecidas como prioridade nos serviços básicos de saúde, objetivando minimizar a carência de informaçôes obtidas pelas famílias e contribuir para a melhoria da qualidade de vida destas. Os ACS ouvidos sustentam que as informaçôes e orientações veiculadas facilitam a vida dos usuários e que, com essas açôes, sentem-se mais úteis perante a pessoa e a família.

Ah, eu acho assim que eu sou útil, que eu sou bastante útil, porque a gente é útil para
as famílias, porque qualquer tipo de informação que você leve eles ficam tão gratos
porque eles são tão desinformados, desencontrados em situaçôes assim, uma pequena
ajuda que a gente dá para eles clareia a mente deles. A visão de como se proceder, de
como fazer (ACS 4).

Os sujeitos demonstram que a luta pela conquista dos direitos aliada ao exercício da cidadania vem fomentar a conquista da postura autônoma dos indivíduos na tomada de decisão na sua própria vida ou na vida de seu familiar, como, por exemplo, em situações em que o indivíduo não consegue fazer suas próprias escolhas. As informações emitidas e recebidas pelos ACS transmitem mensagens dos serviços de saúde para o usuário ou vice-versa, fortalecendo esse elo entre a comunidade e os serviços.

Bachilli, Scavassa e Spiri (2008) ressaltam que, perante a execução do trabalho, os ACS começam a compreender mais e melhor as circunstâncias envolvidas na produção ou supressão de saúde da comunidade, fato que reflete no aprimoramento dos recursos utilizados para contribuir com as famílias, consequentemente gerando reconhecimento, por produzir resultados que culminam com a gratidão dos seus assistidos. Desse modo, os sujeitos buscam atuar nos determinantes do processo 
saúde-doença, de modo a identificar a relação entre os problemas de saúde e as condições de vida, realizando atividades educativas, propondo e implementando açōes intersetoriais. Peres (2006) afirma que os ACS se identificam como educadores e são percebidos pelos usuários como trabalhadores qualificados, fato que se traduz, para o ACS, como valorização e crescimento pessoal.

Os relatos indicam que em algumas situações, as informações emitidas não são absorvidas e isto pode representar grandes obstáculos na prática cotidiana dos ACS, ficando evidente a dificuldade em atingir mudanças de hábito e comportamentos no que diz respeito ao cuidado com a prevenção das doenças e a promoção da saúde.

Com essa epidemia da dengue que está tendo, é uma coisa triste, porque mesmo na nossa micro-área que você passa todo o mês, o mês que a gente entra olha... agora com nós fizemos o arrastão, nós só estamos orientando... porque hoje eles botam reciclados e a gente vai para o arrastão tiramos tudo, e a gente volta, está a mesma coisa. Mas nós como conhecemos nossa micro-área, a gente já sabe que numa determinada casa, você não pode só orientar, você tem que dar uma disfarçadinha e dar uma entradinha... Porque está difícil educar a população (ACS 3).

Quando são alcançados os objetivos traçados nas ações educativas, os sujeitos encontram satisfação no trabalho, sobretudo no que se refere às respostas e aos desdobramentos das informações e orientações emitidas.

Mudança de hábito não é fácil, mas se você tiver uma convicção daquilo que você estiver falando, firmeza e demonstrar carinho pela pessoa e preocupação, interesse, eu acho que você vai ter um retorno melhor do seu trabalho (ACS 11).

Em busca de contextualizar essa temática, recorremos a Freire (1996 p. 62), que enfatiza:

Saber que devo o respeito à autonomia, à dignidade e a identidade do educando e, na prática, procurar a coerência com este saber, me leva inapelavelmente à criação de algumas virtudes ou qualidades sem as quais aquele saber vira inautêntico, palavreado vazio e inoperante.

Os sujeitos entrevistados demonstram que, ao se aproximarem dos problemas das famílias, sentem-se potentes quanto aos encaminhamentos fornecidos por eles, vislumbrando resultado satisfatório para o usuário.

Ah, quando a gente passa as orientaçôes, quando a gente chega na casa leva as informação para eles ... Quando a gente não sabe, a gente busca essa informação e volta lá na casa...Eles recebem essa luz, eles ficam muito felizes, eles ficam contentes, porque às vezes fica meio parados não sabem como proceder, como fazer. Como se fosse uma luz, né, para eles, né? Eles agradecem e eles ficam muito agradecidos. Ficam felizes (ACS 4). 
Segundo Nunes et al. (2002), os ACS utilizam estratégias para implementar ações de educação para a saúde, já que percebem várias formas de resistências por parte da população, sendo essas manifestadas quando não são adotados os comportamentos propostos (alimentares, higiênicos e outros) ou até no caso de oposição deliberada, demonstrada pela recusa em receber membros da equipe no domicílio: "Bom, a maior dificuldade é você tentar educar o morador" (ACS 3).

Sobre essa questão, Wai (2007) afirma que, ao assumirem o papel de profissional de saúde, os ACS tendem a carregar uma idealização da verdade absoluta quanto ao que preconizam, não enxergando o quanto é complexa a tarefa de mudança de hábito da população, que está relacionada a outras práticas, outros saberes, outros profissionais trabalhando em equipe. Segundo Peres (2006), o papel do ACS é contribuir para a construção da autonomia da comunidade diante da própria saúde. Para o autor, há uma diversidade de obstáculos a interferirem na efetivação desse processo; e aponta fatores que podem estar ligados à carga cultural, a valores e às experiências vividas pelo indivíduo.

Nas ações de educação em saúde citadas pelos sujeitos, pode ser observada a ênfase aos aspectos biológicos e curativos, com envolvimento e dedicação à prática medicamentosa, o que sugere a tendência do fortalecimento do modelo hegemônico dos serviços de saúde.

Tem casas que você tem que ir olha: você toma o remédio assim, você toma o remédio assim, você toma o remédio assim. Tem que explicar, se fala que é de doze em doze horas, eles pensam que doze horas, eles têm que tomar assim o dia inteiro. Doze horas naquele dia. Então você tem que explicar (ACS 5).

Percebe-se que existe, na prática cotidiana do ACS, a preocupação com um atendimento de forma humanizada aos indivíduos e suas famílias, cujo enfoque se concentra em dar assistência direcionada à necessidade apresentada.

E procuro fazer o que ele está precisando. Se é de um médico, eu tento levar ele até o médico. Se é de um remédio, eu tento trazer o remédio até ele. Se é de conversar, as vezes é só conversar, as vezes precisa né? A gente fica ali, conversa... passa o tempo... Eu acho que é isso, o mais importante para mim (ACS 10).

Refletindo sobre o processo de trabalho dos ACS e sobre as intencionalidades desses trabalhadores, podemos identificar que há uma preocupação importante por parte destes, com a cobrança em relação ao seu desempenho, que, muitas vezes, está associado ao número de visitas realizadas. A diretriz da estratégia saúde da família propõe, como meta para o agente, visitar mensalmente 100\% 
das famílias cadastradas em sua área de abrangência. No entanto, a preocupação com o cumprimento da solicitação quantitativa pode dificultar a prática de um trabalho mais apurado do ponto de vista da qualidade e do compromisso com a edificação da melhoria da assistência.

Podemos considerar pertinente à prática assistencial do ACS que ela seja conduzida pelos aspectos intersubjetivos trazidos por Merhy (1999), compondose a todo o momento na execução de seu próprio trabalho e em todos os ambientes, seja no domicílio, durante as visitas domiciliares, na UBS ou nos espaços comunitários que ocupam frequentemente. No que se refere à efetivação do cuidado ao usuário, aparece nos discursos a preocupação dos ACS com os aspectos subjetivos, procurando atender às necessidades dos usuários, ao invés de focalizar somente as técnicas e abordagens objetivas.

Rodrigues e Araújo (2008) enfatizam que, ao pensar um novo modelo assistencial em saúde centrado no usuário, é fundamental ressignificar o processo de trabalho, cuja finalidade deve ser mudada, passando a ser este a produção do cuidado, na perspectiva da autonomização do sujeito, orientada pelo princípio da integralidade, demandando, dessa forma, instrumentos como a interdisciplinaridade, a intersetorialidade, o trabalho em equipe, a humanização dos serviços e a criação de vínculos usuário/profissional/equipe de saúde.

Observamos que embora os sujeitos tenham em alguns momentos mencionado a pluralidade do processo saúde-doença e neste, a dinâmica da promoção da saúde, os relatos também revelam que a atuação é mais voltada para a prevenção da doença.

\section{Considerações finais}

Elucidou-se, na presente investigação, a importância do vínculo na prática diária dos sujeitos ouvidos. Na maioria dos relatos, foi explícito, que, sem a credibilidade e a confiança das famílias e dos usuários frente a seu trabalho, não há efetivação de ações. $\mathrm{O}$ estudo sugere que o tempo de permanência na atividade é fator importante para o estabelecimento da assistência proposta. Compreendemos, assim, que se faz necessário melhor entendimento sobre as concepçóes dos profissionais de saúde, sobre suas limitaçôes, autonomia, conceitos, para facilitar a relação usuário-paciente. 
Observamos a convergência dos ACS em direcionarem sua prática assistencial aos princípios religiosos e humanitários, como o da solidariedade, o que pode estar relacionado às experiências anteriores de vida, à idade, ao credo religioso, que parece ser mais acentuado em cidades do interior. Perante os achados, consideramos que os ACS se destacam como grandes mediadores da tecnologia leve.

$\mathrm{Na}$ ótica dos sujeitos entrevistados, a gratificação pelo trabalho está relacionada ao reconhecimento expresso pelos usuários, pelas famílias e pela comunidade, no que se refere ao seu comprometimento e a sua competência para o trabalho. Por outro lado, evidencia-se a incapacidade dos sujeitos em discernir o alcance de seus limites, estando em consonância com outros estudos realizados em outros municípios.

Foram mencionadas pelos participantes, como fator de estímulo, a satisfação e a gratificação pelo trabalho, a resposta positiva dos usuários frente às orientações de prevenção de doenças. Os ACS afirmam se sentirem úteis perante as mudanças favoráveis quanto às condições de saúde e de vida dos indivíduos e de suas respectivas famílias, sobretudo quando estas foram desencadeadas pela sua prática de assistência voltada às orientações na comunidade. No entanto, observa-se que, embora esses profissionais apresentem um bom suporte técnico para o cumprimento de suas ações, ainda falta instrumentalização para o exercício profissional dos ACS, o que dificulta o propósito principal do programa e a melhoria da qualidade de vida da comunidade. Deste modo, podemos considerar que se encontram em construção as políticas de saúde especificamente voltadas à assistência do indivíduo ou da família no âmbito da comunidade, as quais ocorrem mediante a agregação dos ACS nos serviços de saúde, tornando-se assim imaturas as conclusões obtidas sobre as experiências existentes até o momento. As diretrizes e normas estabelecidas para as ações de saúde na comunidade funcionam como norteadoras desse processo, mas estão aquém, para responder a questões mais subjetivas encontradas na assistência ao indivíduo-família-comunidade.

Entretanto, os ACS parecem estar vulneráveis às flutuaçôes de gestão dos municípios, estados e Governo Federal, apresentando inconstância e inconsistência na ideologia do desempenho do próprio papel perante as famílias e a comunidade, não conseguindo, até o momento, inverter o modelo assistencial pautado na doença e na intervenção médica individual. 


\section{Referências}

BACHILLI, R.G.; SCAVASSA, A.J.; SPIRI, W.C. A identidade do agente comunitário de saúde: uma abordagem fenomenológica. Ciência e Saúde Coletiva. Rio de Janeiro, v. 13, n. 1, p. 51-60, 2008.

BARDIN, L. A análise de conteúdo. Rio de Janeiro: Ediçōes 70, 1994. 229p.

BRASIL. Ministério da Saúde. Legislação do SUS. Lei 10.507, de 10 de julho de 2002. Disponível em: <http://dtr2004.saude.gov.br/legislação.php>. Acesso em: 21 set. 2006.

BRASIL. Ministério da Saúde. Legislação do SUS. Portaria GM 648, de 28 de março de 2006. Disponível em: <http://drt2004.saude.gov.br/dab/legislação.php>. Acesso em: 21 set. 2006.

CECÍLIO, L.C.O. As necessidades de saúde como conceito estruturante na luta pela integralidade e equidade na atenção em saúde. In: PINHEIRO R.; MATTOS R.A. (Org.). Os sentidos da integralidade na atenção e no cuidado à saúde. Rio de Janeiro: IMS-UERJ, 2001. p. 113-125. FERRAZ, L.; AERTS, D.R.G.C. O cotidiano de trabalho do agente comunitário de saúde no PSF em Porto Alegre. Ciência e Saúde Coletiva, Rio de Janeiro, v. 10, n. 2, p. 347-355, 2005.

FREIRE, P. Pedagogia da autonomia: saberes necessários à prática educativa. 27ed. São Paulo: Paz e Terra, 1996. 148p.

JARDIM, T.A. Morar e trabalhar na comunidade: a realidade dos agentes comunitários de saúde. 2007. 120p. Dissertação (Mestrado em Ciências) - Faculdade de Medicina, Universidade de São Paulo, São Paulo, 2007.

LIMA, M.A.D.S.; RAMOS, D.D.; ROSA, R.B. et al. Acesso e acolhimento em unidades de saúde na visão dos usuários. Acta Paul Enferm, São Paulo, v. 20, n. 1, p. 12-17, 2007.

LUNARDELO, S.R. O trabalho do Agente Comunitário de Saúde nos Núcleos de Saúde da Família em Ribeirão Preto - São Paulo. 2004. 156p. Dissertação (Mestrado em Enfermagem em Saúde Pública) - Escola de Enfermagem, Universidade de São Paulo, Ribeirão Preto, 2004. MARTINES, W.R.V. Compreendendo o processo de sofrimento no trabalho do Agente Comunitário de Saúde no Programa Saúde da Família. 2005. 162p. Dissertação (Mestrado em Enfermagem na Saúde do Adulto) - Escola de Enfermagem, Universidade de São Paulo, São Paulo, 2005.

MEIRA, R.M.M.B.P. O agente comunitário de saúde: convergências e divergências, na percepção dos próprios agentes, dos médicos, enfermeiros e usuários do serviço. 2008. 161p. Dissertação (Mestrado em Saúde Coletiva) - Faculdade de Medicina, Universidade Estadual Paulista, Botucatu, 2008.

MERHY, E.E. O ato de cuidar: a alma dos serviços de saúde. Campinas, 1999. Disponível em: <http://paginas.terra.com.br/saude/merhy/textos/Cinaematocuidar.pdf>. Acesso em: 13 fev 2007. 
A perda da dimensão cuidadora na produção da saúde: uma discussão do modelo as-

sistencial e da intervenção no seu modo de trabalhar a assistência. Belo Horizonte: SUS, 2007. Disponível em: <http://www.hc.ufmg.br/gids/perda.doc>. Acesso em 20 de março 2007a.

Cuidado com o cuidado em saúde: saber explorar seus paradoxos para um agir manicomial. In: MERHY, E.E.; AMARAL, H. (Org.). A Reforma Psiquiátrica no Cotidiano II. São Paulo: Hucitec, 2007b.

NUNES, M.O.; TRAD, L.B.; ALMEIDA, B.A. et al. O agente comunitário de saúde: construção da identidade desse personagem híbrido e polifônico. Cad de Saúde Pública, Rio de Janeiro, v. 18, n. 6, p. 1639-46, 2002.

PERES, C.R.F.B. O trabalho do agente comunitário de saúde no município de Marília - SP. 2006. 165p. Dissertação (Mestrado em Saúde Coletiva) - Faculdade de Medicina, Universidade Estadual Paulista, Botucatu, 2006.

RODRIGUES, M.P.; ARAÚJO M.S.S. O fazer em saúde: um novo olhar sobre o processo de trabalho na estratégia saúde da família. Disponível em: http://www.observatorio.nesc. ufrn.br/texto_polo05.pdf Acesso em: 10 jan 2008.

SILVA, J.A.; DALMASO, A.S.W. O agente comunitário de saúde e suas atribuições: os desafios para os processos de formação de recursos humanos em saúde. Interface Comum Saúde Educação, Botucatu, v. 6, n. 10, p. 75-83, 2002.

WAI, M.F.P. O trabalho do Agente Comunitário de Saúde na Estratégia Saúde da Família: fatores de sobrecarga e mecanismos de enfrentamento. 2007. 140p. Dissertação (Mestrado em Enfermagem Psiquiátrica) - Escola de Enfermagem, Universidade de São Paulo, Ribeirão Preto, 2007.

WESTPHAL, M.F. Promoção da saúde e prevenção de doenças. In: CAMPOS G.W.S. et al (Org.). Tratado de Saúde Coletiva. 2ed. São Paulo: Hucitec, 2006. p. 635-667. 


\section{Conceptions of community health agents about their health care practices}

This study aimed to identify the representations developed by community health agents (CHA) about their care practices. We used the qualitative research methodology, taking semistructured interviews for collecting data; for data interpretation, we adopted the thematic analysis. Twelve CHA of the Community Agents Program (PACS) from a hinterland town in São Paulo State. The material obtained presented two themes: the bond as working tool and practice based on health promotion and disease prevention. The reports show the importance of the bond in daily practice, emphasizing the humanitarian principles that underlie the actions of solidarity, highlight the feeling of gratification when the work performed is recognized by families and reveal that the interviewed ones have trouble in discerning the scope of its limits. Although these professionals have a good technical support for the fulfillment of their actions, they also show the need for professional instrumentation. We conclude that the guidelines and standards set for the PACS function as guidelines for the health care process, but do not respond to more subjective issues found in the care of individual-family-community. Moreover, the CHA seem to be vulnerable to fluctuations in the municipal, state and federal administration, have inconsistent ideology in playing their own role and cannot reverse the health care model guided by disease and individual medical intervention.

> Key words: community health agents; bond; humanization. 